\title{
Believing and acting on fake news related to natural food: the influential role of brand trust and system trust
}

\author{
British Food Journal 2021 \\ Subhalakshmi Bezbaruah \\ Amandeep Dhir \\ Shalini Talwar \\ Teck Ming Tan \\ Puneet Kaur
}

\begin{abstract}
Purpose - Fake news represents a real risk for brands, particularly for firms selling essential products, such as food items. Despite this anecdotal acknowledgement, the dynamics of the relationship between fake news and brand reputation remain under-explored. The present study addresses this gap by examining the association of consumer values (universalism and openness to change), brand trust, fake news risk and system trust in the context of natural food products.

Design/methodology/approach - The study utilised a cross-sectional survey design and the mall intercept method to collect data from 498 consumers of natural food residing in India. To test the hypotheses, which were grounded in the stimulus-organism-response (SOR) framework, the collected data were analysed using covariance-based structural equation modelling in SPSS AMOS. The conceptual model proposed universalism and openness to change as stimuli, brand trust as an internal state or organism and fake news risk - captured through the tendency of consumers to believe and act on fake news - as a response.
\end{abstract}

Findings - The findings support a positive association of universalism with brand trust and a negative association with fake news risk. In comparison, openness to change has no association with either brand trust or fake news risk. Brand trust, meanwhile, is negatively related to fake news, and this association is moderated by system trust. Furthermore, brand trust partially mediates the relationship between universalism value and fake news risk.

Originality/value - Notably, the present study is one of the first attempts to understand the fake news risk associated with natural food brands by utilising the SOR framework in an emerging market setting. The study provides interesting insights for policymakers, brands and consumers.

Keywords: Brand trust, Fake news, Natural food brands, Openness to change values, SOR framework, System trust, Universalism values

Paper type: Research paper 


\section{Introduction}

The evolution of social media has completely and positively transformed the ways in which consumers communicate and process information (Talwar et al., 2019; Dhir et al., 2017, 2018). At the same time, however, social media has also engendered various negative consequences, among which the emergence of fake news is the most serious of all (Visentin et al., 2019). Fake news is defined as false information that is circulated to readers as authentic and legitimate (Talwar et al., 2019). Scholars argue that fake news mimics the format but not the intent of actual news (Flostrand et al., 2020). The rapid spread of fake news on social media can be attributed to a number of factors, such as economic incentives (Visentin et al., 2019), an individual's social circle and prior beliefs (Chen and Cheng, 2019) and distrust in public institutions (Field, 2018), among others.

The phenomenon of fake news has existed for decades, but both its relevance and prevalence have become more prominent and, indeed, a ubiquitous part of all people's lives, due to its spread on social media and other Internet platforms (Talwar et al., 2019). Underscoring the seriousness of fake news, scholars contend that it is difficult for individuals to determine the accuracy of the information source and the validity of the news content available on social media and other Internet platforms (Kang et al., 2011). Consequently, people tend to believe fake news, which ultimately reduces the credibility and accuracy of institutions and organisations that have an online presence (Flostrand et al., 2020). Thus, fake news poses a significant threat to all such institutions and organisations.

Recently, scholars have begun examining the impact of fake news on brands. The preliminary evidence suggests that fake news poses a significant threat to the existence, image and growth of any brand and to consumers' goodwill towards it (Flostrand et al., 2020). To begin, Flostrand et al. (2020) emphasise that fake news presents a complex threat to brands because exposure to a single piece of fake news can increase consumers' belief in the accuracy of subsequent pieces of false information or narratives. Similarly, Talwar et al. (2019) argue that fake news shared by consumers can have quite damaging and negative consequences for any brand. Consistent with this argument, a recent report suggested that the sharing of fake news has cost the global economy close to \$78bn (Sullivan, 2019). Furthermore, brands lose almost $\$ 235 \mathrm{~m}$ annually by unknowingly running advertisements alongside fake news, which causes their own trust and credibility among customers to suffer (Sullivan, 2019). For these reasons, brands must explore effective strategies for reducing the ill effects of fake news. This is especially important because brand image, which brands cocreate with consumers, is representative of consumers' perceptions.

Scholars have noted that online fake news primarily targets brands that specifically provide essential offerings, such as food, health and beauty (de Regt et al., 2019). They argue that fake news builds false narratives accusing such brands of exploiting regulatory loopholes and conducting pseudo research (de Regt et al., 2019). For instance, Rao (2019) revealed that food brands must fight lengthy legal battles to counter the spread of fake news and misinformation about their products' ingredients. A prime example of this is PepsiCo, which has fought many legal battles against the spread of vicious news about its products, including a claim that Pepsi products contain plastic particles (Singh, 2018). A possible reason for the generation, propagation and, finally, belief in fake news related to these brands could be that they offer products/services that are used by a large number of people. 
Another product class that has been the victim of the spread of misinformation and fake news is natural food products. Recently, in India, for example, a natural food brand developed a product that claims to boost the immune system against COVID-19, but many questioned the effectiveness of the product (Chandna, 2020). Similarly, in the past, some of the same company's natural food products were banned following the spread of fake news alleging that they contained excessive chemical components (Gautam, 2018). Increasingly negative attitudes towards chemical content in food and the increasing tendency to consume environmentally friendly products has, in turn, increased the popularity of natural food among consumers (Migliore et al., 2018; Moscato and Machin, 2018). In fact, the natural food industry is now worth $\$ 75$ bn (Chambers et al., 2019). Natural food products include organic foods and products that are perceived as less processed and free from harmful chemicals, such as pesticides, antibiotics, genetically modified foods and additives (Kumar et al., 2021a, b). We argue that natural food products are more prone and sensitive to being targeted by fake news because they suffer from "link loss", which means that their origins are not clearly defined, and as a result, consumers are even more skeptical (Mathiot, 2018; Bobo and Chakraborty, 2016). Similarly, consumers tend not to accept the effectiveness of natural food and its associated high prices (Carocho et al., 2015), which makes these products susceptible to fake news. Since the natural food industry represents an important business sector from both the health and economic perspective, it is crucial to safeguard it from the negative consequences of fake news.

A review of the extant literature reveals that the academic research regarding the impact of fake news on brands and the strategies that may be effective in countering fake news remains in an embryonic stage. Indeed, it offers limited insights and exhibits several visible gaps. Based on our extensive literature review, we identify four key gaps: first, although the phenomenon of fake news continues to increase, at present, empirical studies examining the resultant effect of fake news on brands - particularly in the context of natural food brands, which have been one of the most prominent targets of fake news and misinformation campaigns - are insufficient. To elaborate further, brands are vulnerable to fake news, which negatively impacts consumers' purchase decisions (Visentin et al., 2019). Still, much less is known about the effect of fake news on brands, especially from the brand's marketing communications perspective (Visentin et al., 2019; Chen and Cheng, 2019). Second, the recent literature has suggested that consumers tend to believe and share fake news because of their high trust in it (Talwar et al., 2019). However, scholars have yet to identify consumers' conative actions that are exposed to fake news regarding natural food. Third, it is not known what factors influence the tendency of consumers to believe and act on fake news regarding natural food. In other words, the extant literature has, as yet, failed to explore the risk represented by fake news when consumers not only perceive it to be true but also act upon it. Finally, fake news as a phenomenon has been studied more from the angle of journalism, public policy and political science (Chen and Cheng, 2019), while scholars have conducted relatively few studies on fake news from the perspective of marketing or brand management (Mills and Robson, 2019; Chen and Cheng, 2019; Flostrand et al., 2020).

We propose to addresses these research gaps by examining the antecedents of key variables associated with the brand, i.e. brand trust and the tendency of consumers to believe and act upon fake news concerning natural food. Brand trust enables us to capture the ability 
of a brand's reputation to fortify the brand against the onslaught of fake news, while the tendency of consumers to believe and act upon fake news enables us to capture the risk that fake news poses for natural food brands. To propose the antecedents of the identified outcome variables, we draw upon basic human values theory (Schwartz, 1992) to identify two crucial values - universalism and openness to change. Next, to conceptualise the ways in which the identified variables associate with one another and the reasons for their associations, we draw upon the stimulus-organism-response (SOR) theory (Mehrabian and Russell, 1974), which has been utilised to explain human behaviour and decision-making in varied contexts, including natural food consumption (Kumar et al., 2021a, b; Tandon et al., 2021).

Accordingly, we propose human values - namely universalism and openness to change as the stimuli (S), brand trust as the internal or organismic state $(\mathrm{O})$ of consumers and, finally, the tendency to believe and act on fake news (fake news risk) as the consumers' response (R). In addition, to better reflect the ways in which consumers process fake news, we identify system trust as another variable of interest. This is based on the prior literature, which has suggested that a lack of trust in public institutions further increases brands' vulnerability to fake news (Field, 2018). Recognising that individual differences in the level of system trust could exist, we propose to examine the moderation effect of system trust. The purpose and objectives of our study can be summarised through four main research questions (RQs): RQ1. Do universalism and openness to change associate with brand trust and fake news risk in the context of natural food brands, and if so, how? RQ2. What is the nature of the association between brand trust and fake news risk? RQ3. Does brand trust serve as an intervening mechanism between the above values and fake news risk, and if so, how? RQ4. Does system trust moderate the relationships between universalism, openness to change, brand trust and fake news risk, and if so, how?

The proposed model, which was tested by analysing cross-sectional data collected from 498 existing consumers of natural food, offers three significant contributions to the literature. First, this is one of the first empirical studies to investigate the issue of fake news in the context of natural food brands. It is, moreover, possibly the first empirical study to examine the factors that may influence consumers' tendency to believe and act on fake news (fake news risk). Second, this is the first study to utilise a combination of two well-known theories, namely, basic human values theory and the SOR framework, to theorise the antecedents of brand trust and fake news risk. Third, most of the prior literature on consumption behaviour focuses on developed countries (Molinillo et al., 2020). However, natural food consumption is a global phenomenon that is affected by brand trust, human values, fake news and consumers' level of trust in their government's control systems. Therefore, we have focused on natural food brands in India, which is an under-explored emerging country with a rising level of consumer conscience. Because food is not merely a functional aspect of human lives but also an inherently cultural construct, it may influence consumers' food consumption behaviours and their perceptions in emerging markets differently than in developed countries (Asioli et al., 2017).

The rest of the article is structured as follows: Section 2 provides an exposition of the background literature, including the literature related to natural food products, fake news and brands as well as the two theories. Section 3 outlines the development of the hypotheses, while Section 4 discusses data and methods. Section 5 presents the results followed by a discussion in Section 6 and the conclusion in Section 7. 


\section{Background literature}

\subsection{Natural food products}

Natural foods are food items that are organically grown to maintain the foods' naturalness. They contain low or no traces of preservatives and added colours and are thus considered a healthier consumption option than conventional food products (Backstrom et al., 2004). From an environmental perspective, Rozin et al. (2012) contend that natural food products are free of negatives, such as human intervention (genetically modified organisms), pollution and additives. The growing global demand for natural food across diverse consumer segments is, therefore, hardly surprising (Kumar et al., 2021a, b; Roman et al., 2017). Perceiving natural food products to be fresher, more nutritious, safer, healthier, free from chemical substances and less environmentally harmful than conventional food products, consumers tend to prefer natural food and are willing to pay a premium for it (Moscato and Machin, 2018). Recognising that 'naturalness' is representative of overall human well-being, which includes both emotional and physical health (Migliore et al., 2018; Moscato and Machin, 2018), scholars have even equated natural food with spiritual and pure food (Rozin et al., 2012).

The extant literature on consumer behaviour towards natural food offers a significant understanding of the motives behind natural food consumption (Kumar et al., 2021a, b; Michel and Siegrist, 2019; Moscato and Machin, 2018; Roman et al., 2017; Asioli et al., 2017; Rozin et al., 2004). According to these research studies, consumers act on their 'natural choice,' which is governed by the distinction between ideation and instrumental beliefs. Instrumental beliefs, in turn, are supported by intrinsic superiority, which causes individuals to believe that the consumption of natural food is superior. Ideational beliefs, on the other hand, are free of instrumental beliefs and are based only on moral superiority (Migliore et al., 2018). However, ideational values are considered to be the major motivation behind natural food consumption (Rozin et al., 2004).

\subsection{Fake news and brands}

Fake news refers to misinformation that is spread about a person, an event or, in the present context, a brand. The typology of fake news can consist of genres such as satire, parody, propaganda, advertising, and so on (Talwar et al., 2019). Such genres can be broadly divided into two forms, namely, intentions to mislead and facticity (Visentin et al., 2019). Intentions to mislead represent deliberate attempts to spread false information. Facticity, on the other hand, is a gauge of how much of the fake news content is actually based on facts (Visentin et al., 2019).

Studies have revealed that consumers, driven by lazy thinking (Pennycook and Rand, 2019), do not always critically analyse the news (or information) they consume. Thus, brand managers should not expect consumers to actively differentiate between real news and fake news about their brands (Flostrand et al., 2020). When exposed to fake news, consumers may simply believe it to be accurate, which, in turn, negatively affects the concerned brand and, in particular, endangers consumer-brand relationships, including brand value and brand trust (Mills and Robson, 2019). For example, a decade ago, the shares of Apple Inc. fell 10\% in 10 min due to fake news stories claiming that Steve Jobs had suffered a heart attack (Hargreaves, 2008). More recently, in 2019, the Tata group, India's largest conglomerate, fought misinformation regarding the presence of cyanide in their salt products (Rajagopal, 2019). Scholars have also shown that exposure to fake news elicits human emotions such as 
disgust, fear and anger (Vosoughi et al., 2018). Such negative emotions further deteriorate consumers' perceptions of a brand and thus impact their purchase decisions (Visentin et al., 2019). Furthermore, fake news spread via various media raises the cost of customers' information searches, broadens their consideration set to rivals and, ultimately, raises their psychological dangers (Flostrand et al., 2020). Because consumers perceive a brand's image as a sum of their own perceptions, fake news entails a risky proposition for the brand and for its internal and external stakeholders (Chen and Cheng, 2019).

In the specific context of natural food products, the role of fake news can be understood first by explicating the typical nature of these food products. It is important to note that although the growth and demand for natural food have increased, certain aspects of these products continue to make consumers skeptical and hesitant. Highlighting some of these aspects, Carocho et al. (2015) noted that factors such as the actual effectiveness of the natural food, its price, ambiguity over the product's origin and legislative issues might impact consumers' intentions. Similarly, Mathiot (2018) argued that in the case of natural foods suffering from "link loss", i.e. a lack of clarity about their origins or production, consumers may develop strong mistrust in their production process. Such factors leave natural food brands vulnerable to fake news by increasing consumers' perceived risk. Such distrust or scepticism can make consumers more susceptible to fake news, which might reinforce their doubts. However, sufficient a priori information does not exist to allow us to comment on consumers' tendency to believe and act on fake news, and this paucity of knowledge demands deeper exploration into the ways in which natural food brands and their consumers behave when exposed to fake news about such brands. In this regard, the present study explores whether consumers choose to act on the fake news they encounter about natural food.

\subsection{Basic human values theory}

Value is a complex and contentious notion that is widely applied in the social sciences.

Schwartz's (1992) seminal work identified ten universal individual values based on three basic individual requirements. These requirements are (1) the need to survive and exist within a group, (2) the need for social interactions and (3) biological needs. Though human values are universal, individuals prioritise values differently, which thus makes a one dimensional perspective on values insufficient (Sepasi et al., 2021). This understanding further impelled efforts to understand the dynamic relationships among these values. Schwartz (1995) suggested that values are further categorised into four broader core values: self-transcendence, self-enhancement, conservation and openness to change. These categories act as an individual's moral compass in evaluating people, society and life events (Sakdiyakorn et al., 2021). The above theory has been extensively used to explore which values drive an individual to take certain actions and make certain decisions, especially in the domain of marketing and decision-making (Fritzsche and Oz, 2007; Sepasi et al., 2021). Since the consumption of and preference towards natural food are cognitive constructs, we postulate that consumers rationally choose natural food based on a set of human values that shape their purchase decisions.

\subsection{Stimulus-organism-response (SOR) theory}

The SOR framework is a neo-behaviouristic approach that indicates how environmental stimuli (S) affect an individual's internal cognitions (O), which, in turn, lead to the individual's behavioural response (Mehrabian and Russell, 1974). The SOR framework has been widely 
used across social science disciplines to explain the ways in which consumers construct their decision-making processes (Kumar et al., 2021a, b). The wide acceptability of the framework derives from its consideration of the emotional, affective and cognitive processes in which an individual engages regarding a specific behaviour (Kim et al., 2020). The SOR framework has, in particular, been applied to understand food consumption and food-related consumer behaviour. SOR has been utilised to understand consumers' purchase intent towards natural food and associated food safety incidents (Zheng and Liu, 2019) as well as the effect of food aromas on consumers' emotions, perceptions and choices of foods to consume (Ouyang et al., 2018). The present study utilises the SOR framework for the following reasons: (1) the SOR framework incorporates both cognitive and affective states in the form of attitude and desire, which enables us to better understand the phenomena in question and (2) according to the framework, external stimuli influence an individual's internal state, thus, shaping the individual's desired behaviour through his or her actions ad decisions. This is important because the present study evaluates the notion of natural food products as a whole.

\subsection{Extending basic human values theory and SOR theory to the present context}

The present study proposes to examine the association of universalism and openness to change with brand trust and fake news risk in the context of natural food products. In addition, it examines the association between brand trust and fake news risk. Finally, it examines the mediation effect of brand trust on the association between the above values and fake news risk as well as the moderation effect of system trust on the association between universalism, openness to change and fake news risk and on the association between brand trust and fake news risk. The proposed model also controls for the confounding effects of age and gender.

Based on the theory of basic human values, we propose universalism and openness to change values as stimuli (Schwartz, 1992) because these values are considered influential in predicting consumers' attitudes towards natural food consumption (Thøgersen et al., 2017).Universalismis a value that captures consumers' understanding of, appreciation of and tolerance for the wellbeing of people and the environment (Aertsens et al., 2009). Previous studies posit that proenvironment opinions positively predict pro-natural food beliefs (Lea and Worsely, 2005).

Universalism is also a dominant value that guides consumers to opt for naturally occurring, less processed food (Thøgersen, 2007). Openness to change, meanwhile, is associated with consumers' thoughts, feelings and propensity to eek novel experiences. According to Hansen et al. (2018), openness to change includes stimulation and self-direction values. Individuals with a high level of openness to change view the consumption of natural food products as an opportunity for progress (Ramasamy et al., 2019). Tiainen et al. (2013) further demonstrated the favourable relationship between openness to change and healthy eating habits; people who score high on openness to change consume more nutrients and exhibit fewer unhealthy eating behaviours. Hence, we propose that universalism and openness to change values are potential motivators and stimulants of consumers' trust in natural food product brands.

We captured consumers' internal state or organism through brand trust. This construct has been shown to be a motivational factor for natural food purchase intentions, including intentions to purchase food with natural labels (Konuk, 2018). Recognising trust as a crucial factor in this process, scholars in this domain have extensively examined the association between brand trust and consumers' decision-making (Hobbs and Goddard, 2015; Verneau et al., 2016). Because consumers cannot directly verify the claims of natural food products 
(such as quality or certifications), their trust is based upon two aspects: brand trust and trust in the government system. The extant literature supports this argument by documenting the positive association between these two aspects of trust and consumers' confidence in food (Lassoued and Hobbs, 2015; Ngo et al., 2020a, b). Especially in emerging countries, food chains for distributions mostly operate through traditional markets, where branded and nonbranded food products are sold together. This context is important because consumers operating within it are more prone to lose their trust in brands. Given the importance of brand trust in consumer behaviour, we argue that it would be quite useful to understand its role in the context of fake news related to natural food products. Therefore, we propose to investigate not only the direct association of brand trust with the identified values and with fake news risk but also the possibility of the mediational effect of brand trust on the association between these values and fake news risk. Next, since our primary objective in this study is to examine consumers' perceptions of fake news and their subsequent decisions when exposed to such news, we identify fake news risk with response in the SOR model. This choice is grounded in the reasoning that fake news risk captures the tendency of consumers to believe in and act on fake news circulating about a particular product.

Finally, we identify system trust as a moderating variable. The literature suggests that consumers' trust in food depends on system trust (Ngo et al., 2020a, b). Acknowledging that trust is a complex aspect, scholars have suggested different dimensions that fall under system trust (Yee et al., 2005; de Jonge et al., 2008). These dimensions are competence, credibility, reliability, integrity, benevolence and ability to provide information. For the current study, we consider system trust using these dimensions. While system trust has been recognised as a key component in fostering consumers' confidence in their food choices, studies investigating the role and impact of system trust on consumer food purchase decisions remain scarce.

\section{Hypotheses development}

The proposed research model and a brief description of all constructs are presented in Figure 1 and Table 1, respectively.

Figure 1. Hypothesised research model

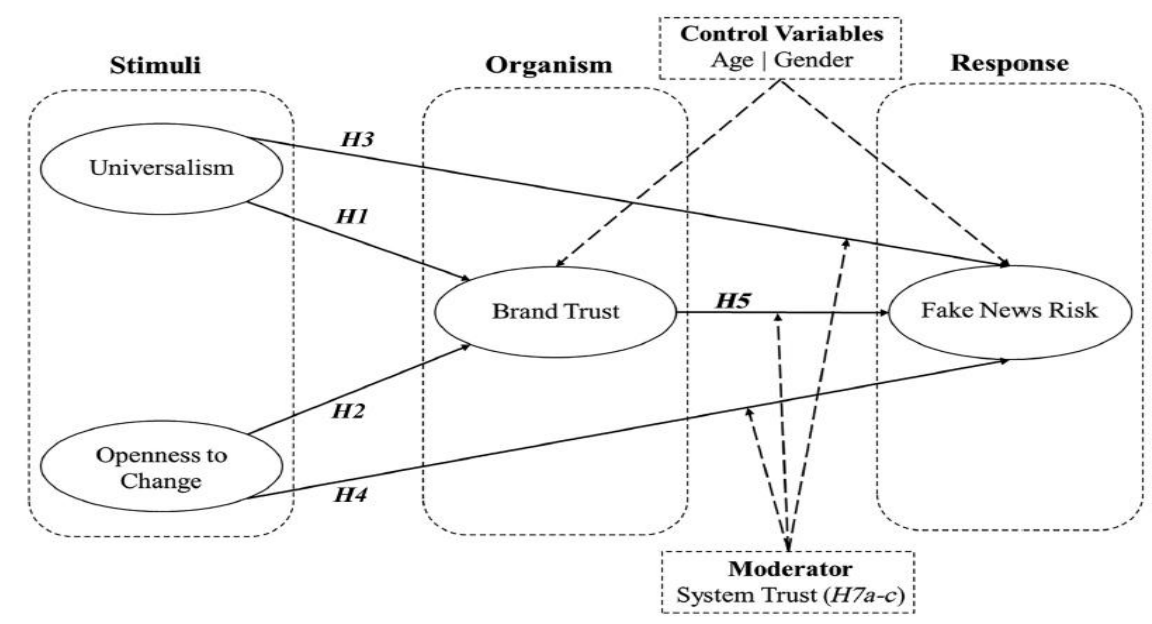


Table 1. Brief description of study constructs

\begin{tabular}{|c|c|c|c|}
\hline $\begin{array}{l}\text { SOR } \\
\text { dimension }\end{array}$ & $\begin{array}{l}\text { Study } \\
\text { constructs }\end{array}$ & Brief description & Reference(s) \\
\hline \multirow[t]{2}{*}{ Stimuli } & Universalism & $\begin{array}{l}\text { An individual's tendency to understand, } \\
\text { appreciate and protect nature and the } \\
\text { environment }\end{array}$ & Schwartz (1992) \\
\hline & $\begin{array}{l}\text { Openness to } \\
\text { change }\end{array}$ & $\begin{array}{l}\text { An individual's perceptions, feelings and } \\
\text { tendencies to accept new experiences }\end{array}$ & $\begin{array}{l}\text { Schwartz (1992), } \\
\text { Hansen } \text { et al. (2018) }\end{array}$ \\
\hline Organism & Brand trust & $\begin{array}{l}\text { An individual's psychological state } \\
\text { characterised by a set of thoughts and } \\
\text { perceptions for a brand that is considered } \\
\text { credible and benevolent }\end{array}$ & $\begin{array}{l}\text { Gurviez and Korchia } \\
(2002)\end{array}$ \\
\hline Response & $\begin{array}{l}\text { Fake news } \\
\text { risks }\end{array}$ & $\begin{array}{l}\text { An individual's tendency to avoid and distrust a } \\
\text { brand when exposed to fake news concerning } \\
\text { that brand }\end{array}$ & $\begin{array}{l}\text { Talwar et al. (2019), } \\
\text { Kumar et al. }(2021 \mathrm{a}, \mathrm{b})\end{array}$ \\
\hline
\end{tabular}

\subsection{Values and brand trust $(S-O)$}

Universalism refers to an individual's appreciation, understanding and protection of and tolerance towards the well-being of nature and the environment (Schwartz, 1992; Aertsens et al., 2009). In the context of food consumption, universalism is the dominant guiding value that influences consumers' attitudes, especially towards natural food consumption (Thøgersen et al., 2017; Thøgersen, 2007). Scholars have also suggested that of all values, universalism explains the most variance in consumption behaviour (Thøgersen and Zhou, 2012) - perhaps because consumers' favourable attitudes towards natural food are rooted in their value systems and beliefs (Thøgersen et al., 2017). On the other hand, brand trust refers to consumers' propensity to rely on the ability of a brand to perform its objective (Chaudhuri and Holbrook, 2001). Brand trust is a cognitive component (Casalo et al., 2007) and an important aspect of brand loyalty and favourable consumer brand relationships (Fournier, 1998). Consumers develop brand trust based on their positive beliefs and expectations regarding a brand (Verneau et al., 2016). Based on a brand's credibility, consumers who have placed their trust in a natural food brand are more likely to purchase the brand's products in the future (Lassoued and Hobbs, 2015).

Because universalism as a value motivates natural food consumption as a more environmentally friendly alternative to conventional food (Kim et al., 2019), it is reasonable to expect universalism to increase consumers' trust in natural food brands. In other words, it is plausible to anticipate a positive association between universalism and brand trust for natural food brands that offer foods known to be environmentally friendly and less processed without any harmful additives (Van Huy et al., 2019). Hence, we propose the following:

\section{H1. Universalism is positively associated with brand trust.}

Openness to change is associated with individuals' thoughts, feelings, actions and propensity to accept novel experiences (Tiainen et al., 2013; Hansen et al., 2018; Ramasamy et al., 2019). Underscoring its importance, Schwartz and Sagiv (1995) called openness to change a higher order value. The extant literature has examined openness to change in varied contexts, including natural food consumption. For instance, Hansen et al. (2018) suggested that 
consumers with high levels of openness to change are more inclined towards modern food than towards conventional food, and they are also more willing to consume natural food.

Because consumers with high levels of openness to change also seek sensational and hedonic pleasures in their experiences, their interest in natural food could represent their sensational and hedonic needs (De Pelsmacker et al., 2016). In addition, scholars note that openness to change indirectly relates to consumers' purchase intentions towards green products Mainardes et al., 2017) and transforms their health consciousness into their food identity (Hansen et al., 2018).

Presenting another aspect of consumers' decision-making, Nasir and Karakaya (2014) argued that consumers' lack of trust in certifications and labels is one reason that consumers eschew natural food products. In other words, consumers seek reassurance that their choices are correct. This can be taken to imply that consumers with a high level of openness to change would be more willing to consume natural food to satisfy their hedonism, stimulation and self direction values if they trust the product being offered. Put differently, consumers who are open to change would seek signals that enhance their brand trust in the natural food brand under consideration. Therefore, we speculate that openness to change will have a positive relationship with brand trust towards natural food products that come with labels specifying their quality, content and origin. Based on the above discussion, we propose the following:

\section{H2. Openness to change is positively associated with brand trust.}

\subsection{Values and fake news risk $(S-R)$}

Fake news is described as fabricated, false information created and circulated in a way that makes it appear legitimate and authentic (Talwar et al., 2019). Recipients of fake news, particularly in the online environment, are susceptible to believe and be influenced by such news because they are constantly bombarded with information, which creates information overload and fatigue (Talwar et al., 2019). Such fatigued individuals experience a loss of energy, exhaustion and boredom, which, in turn, inclines them to believe and share fake news without exerting additional effort to authenticate it (Talwar et al., 2019). Similarly, individuals tend to share fake news without critically validating or analysing it if they have high levels of trust in the source (Peterson, 2020). Pennycook and Rand (2019) also argued that individuals suffering from cognitive overload are unlikely to critically analyse a message before sharing it on social media. This tendency of individuals to accept as true and share any piece of fake news they receive leaves brands even more vulnerable to any fake news related to them that surfaces in the media (Peterson, 2020).

However, individuals with a higher level of universalism can be expected to behave differently - i.e. to authenticate any information they receive before acting on it or sharing it. We anticipate this on the basis of prior findings that universalism causes individuals to be concerned for the general well-being and protection of others (Thøgersen et al., 2017). Supporting this view, Farrell et al. (2019) suggested that universalism disinclines individuals to believe information without their personal authentication and thus drives them to verify news and information sources. For these reasons, we posit that consumers who are guided by their universalism are less likely to believe in and act on fake news without adequate verification. This implies that individuals with high levels of universalism will have low fake news risk. Thus, we hypothesise as follows: 


\section{H3. Universalism is negatively associated with fake news risk.}

Openness to change motivates individuals to pursue their own emotional and intellectual interests in new directions (Schwartz, 1992). Individuals with a higher level of openness to change exhibit independent lifestyle choices because they anticipate and value the potential rewards such changes may bring. However, individuals' cognitive and behavioural flexibility in managing change is a crucial component in their openness to change (Gupta and Arora, 2017). Such individuals are also driven by hedonic pleasure; it is thus likely that such individuals consume natural food as a way to display their superior choices in society. The prior literature has confirmed that openness to change has a significant impact on consumers' purchase decisions (Kahle et al., 1986). It is important to note that, for people who are open to change, the end goal is more important than the decision process itself, thus making them less inclined to evaluate the validity of a product's information before purchasing it. This, in turn, causes them to process pieces of information before authenticating them. Adopting another perspective, it is important to note that not all self-directed behaviour is analytical, which causes individuals who are driven by openness to change to engage less in critical thinking (Bronstein et al., 2019).

Schwartz (1992) observed that the unpredictability of life based on one's own thoughts and emotions is captured by openness to change. These emotions also incline such individuals to become early adopters of new products (Wang et al., 2008). Based on the above argument, we propose that consumers who are guided by openness to change are more likely to believe fake news without processing the information analytically. Thus, we postulate the following:

\section{H4. Openness to change is positively associated with fake news risk.}

A brand is an organisation's most valued asset; thus, maintaining the brand's reputation represents an utmost priority, particularly in the online space. Scholars have revealed that products and brands face grave consequences from online fake news (Talwar et al., 2019). The risk for brands comes from the fact that exposure to fake news elicits negative emotions among consumers (Vosoughi et al., 2018) and increases their perceived risk (Flostrand et al., 2020). Fake news also erodes consumers' confidence in the brand, thereby triggering them to switch to competitive brands (Flostrand et al., 2020). However, scholars argue that brand trust can help to reduce uncertainty, particularly if a trusted brand relationship drives consumers' loyalty, brand love and overall positive attitude towards the brand (Chen and Cheng, 2019). This implies that consumers of natural food products who have high brand trust would be less likely to blindly believe in and act upon any fake news that they receive about the concerned brand. In other words, the existence of trust in a brand is likely to make consumers less vulnerable to fake news, lowering fake news risk for their trusted brand. Hence, we hypothesise as follows:

\section{H5. Brand trust is negatively associated with fake news risk.}




\subsection{Mediation effect of brand trust}

Brand trust represents consumers' readiness to believe that the trusted brand acts responsibly and will fulfil the promises it has made to consumers (Chaudhuri and Holbrook, 2002). As an outcome of consumers' previous experiences with a given brand, brand trust contributes towards building positive consumer-brand relationships that protect the brand as well as consumers from uncertainties. In the context of food consumption, brand trust represents an important cognitive aspect that further improves the consumer-brand relationship and reinforces consumers' trust over time via the accumulation of positive experiences (Verneau et al., 2016).

Because brand trust is a cognitive construct, it is reasonable to expect that it will be affected by universalism and openness to change, which are inherent human values that influence consumers' cognitive and conative actions (Thøgersen et al., 2015). Consumers with a higher level of universalism will tend to put their trust in natural food brands because they consider these brands to be purer, cleaner and healthier than conventional food brands. Similarly, a higher level of openness to change will motivate consumers to acquire newer experiences, including the consumption of trusted natural food brand products.

As argued in the preceding section, brand trust is likely to decrease the tendency of consumers to believe in and act on any false or misleading information they might encounter about a trusted brand. This indicates that brand trust is likely to be negatively associated with fake news risk. Given the possibility of a positive association between values and brand trust, a negative association between values and fake news risk, and a negative association between brand trust and fake news risk, we are eager to examine the mediation effect of brand trust. To express it differently, we expect that in addition to the direct associations mentioned above, brand trust also acts as an intervening mechanism - i.e. a pathway for the transmission of indirect effects between the two values and fake news risk. Hence, we propose the following:

\section{H6a. Brand trust mediates the association between universalism and fake news risk. H6b. Brand trust mediates the association between openness to change and fake news risk.}

\subsection{Moderation effect of system trust}

System trust represents consumers' trust in government and institutions that enables them to feel safe and be confident about their social transactions (Pennington et al., 2003). Prior research has suggested that more than one type of trust affects consumer decision-making in the context of natural foods consumption (Nuttavuthisit and Thøgersen, 2017). For instance, Sassatelli and Scott (2001) argued that trust can be either embedded (traditional and personal) or disembedded (universalistic). The embedded version of system trust refers to the concept of the system as a component of society in which the market works on the basis of "fairness", whereas the disembedded form of system trust is rooted in institutions that assure the safety of consumers by providing regulatory and legal norms and reducing the uncertainty associated with food products (Pennington et al., 2003).

Examples of system trust include trust in government, certifications, seals and stamps of approval from vendors. Previous studies have found that consumers who exhibit weak system trust have lower intentions to purchase natural foods because they are sceptical 
about such products' benefits (Nuttavuthisit and Thøgersen, 2017). Pennington et al. (2003) also argued that a high level of system trust could lead to positive behaviour and a positive consumer attitude towards natural food brands. However, consensus is lacking about the moderating role of system trust. For instance, Lassoued and Hobbs (2015) reported a positive association between system trust and confidence in food safety. According to Ngo et al. (2020a, b), moreover, system trust has a direct impact on brand trust. Apart from the food consumption area, however, Hansen et al., (2018) evaluated the moderating effect of system trust on financial knowledge, healthiness and satisfaction with bank services, concluding that system trust had no moderation effect; if people had more trust in the banking system, they trusted the bank (institution).

The above studies thus yield inconsistent results regarding the role of system trust. Based on our review of the literature, we expect system trust to affect the strength of the associations between values, brand trust and fake news risk in the context of natural food products. Moreover, earlier studies noted that if a customer places his or her trust in a brand, the customer will be more resilient to fake news about the brand. Hence, we propose the following:

H7a. System trust moderates the association between universalism and fake news risk. H7b. System trust moderates the association between openness to change and fake news risk.

H7c. System trust moderates the association between brand trust and fake news risk.

\subsection{Control variables}

Consistent with prior studies suggesting that socio-demographic variables may affect consumers' behaviour and decision-making processes related to food consumption (Kumar et al., 2021a, b; Tandon et al., 2021; Talwar et al., 2021), the proposed model controls for the confounding effects of age and gender. Especially in terms of natural food consumption, socio-demographic variables, such as age and gender, have a significant impact on consumers' final purchase decisions (Kumar et al., 2021a, b). Hence, the present study utilises age and gender as control variables while testing the proposed hypotheses.

\section{Data and method}

\subsection{Data collection}

This study used a structured questionnaire that was developed by adapting existing scales from the extant literature. The questionnaire instrument employed a five-point Likert scale from "strongly disagree" as 1 to "strongly agree" as 5 to measure consumers" perceptions of all study constructs. Two screening questions were used to ensure that the participants were suitable for the present study: (1) participants needed to know what natural food is and (2) they needed to consume natural food and exhibit an awareness of different brands that sell natural food in India. Two natural food experts and three professors specialising in retail and marketing were enlisted to assess the validity of the survey instrument by providing feedback and suggesting amendments to the survey questions. A pilot test was also conducted with 15 users representing the target group of consumers identified by the study. Based on feedback from the pilot study, we made minor alterations in the language of the questionnaire. 
The study was conducted in India. The choice of India as the geography of interested is driven by the fact that it is deeply rooted in the practice of Ayurveda as a holistic alternative food and nutrition system, which consistently inclines consumer behaviour and preferences towards naturally grown foods, herbs and associated healthy substitutes (Jaiswal and Williams, 2017). In addition, India is among the fastest-growing emerging markets in this category, as confirmed by recent reports. Globally, the natural food market is valued at US\$ 201.77bn, and in 2020, India accounted for US\$ 849.50m of this total (Expert Market Research, 2020). Data were collected through the mall-intercept method, wherein respondents were recruited outside of large food retail stores selling a variety of natural food brands. Of 550 total responses received, 498 were considered suitable for the analysis.

\subsection{Data analysis}

Consistent with much recent research (Talwar et al., 2020), this study utilised a two-step method for data analysis through IBM AMOS 25 and SPSS 25. A total of 550 questionnaires were collected. After removing the outliers and incomplete responses, 498 responses were retained for the final analysis. The data were first coded, cleaned and prepared for SPSS to assess for normality, multicollinearity, skewness and kurtosis (Hair et al., 2014). The variance inflation factor indicated the absence of multicollinearity in the collected data. The study participants were natural food consumers whose ages ranged from 22 to 45 years (mean age 533.5 years). Table 2 below presents the demographic profile of the respondents.

\section{Results}

\subsection{Common method bias}

Because data on the independent and dependent variables were gathered simultaneously, common method bias was possible. Therefore, Harman's single-factor test was conducted. The results showed that a single factor explained $27.89 \%$ of the total variance, which is much lower than the threshold value of $50 \%$, and precluding the risk of common method bias (Podsakoff et al., 2003).

\subsection{Measurement model and validity and reliability analyses}

A confirmatory factor analysis (CFA) was conducted to determine the maximum likelihood estimation (see Table 3). The model fit values were observed at $\chi 2 / \mathrm{df}=1.37$, TLI $=0.99$, CFI $=0.99$ and RMSEA $=0.03$, suggesting an adequate model fit (Tabachnick et al., 2007; Hair et al., 2014). In addition, the convergent and discriminant validity were examined. The average variance extracted (AVE) and the composite reliability (CR) exceeded 0.5 and 0.7 , respectively, and thus, fell within the acceptable range (Fornell and Larcker, 1981). Table 4 presents the AVE and CR values for each construct. Discriminant validity was also established because the square root of each AVE value exceeded its correlation values with other variables (Fornell and Larcker, 1981). This was further validated via the heterotrait-monotrait ratio of correlations (HTMT) analysis (see Table 5; Henseler et al., 2015).

\subsection{Control variables}

The results indicated that the socio-demographic variables for which the study controlled i.e. the age and gender of the respondents - were not statistically significant and thus did not have any confounding effect on the resultant dependent variable, fake news risk. In comparison, age had significant confounding influence on brand trust, while gender did not. 
Table 2. Demographic profile

\begin{tabular}{llc}
\hline Demographic measures & Category & Percentage (Frequency) \\
\hline \multirow{2}{*}{ Age } & $22-25$ years & $20.7(103)$ \\
& $26-28$ years & $26.5(132)$ \\
& $29-35$ years & $27.7(138)$ \\
& $36-40$ years & $10.6(53)$ \\
Gender* & $41-45$ years & $14.5(72)$ \\
& Female & $46.0(229)$ \\
Household monthly income (in INR) & Male & $53.4(266)$ \\
& Less than 10,000 & $5.6(28)$ \\
& $11,000-25,000$ & $7.8(39)$ \\
& $26,000-35,000$ & $8.0(40)$ \\
& $36,000-50,000$ & $14.9(74)$ \\
Academic qualification & $51,000-65,000$ & $13.7(68)$ \\
& $66,000-75,000$ & $10.4(52)$ \\
& $76,000-90,000$ & $9.6(48)$ \\
& $91,000 \&$ above & $29.9(149)$ \\
& High school & $2.0(10)$ \\
& Senior school & $7.4(37)$ \\
Note(s): INR = Indian rupee; *Some respondents did not report their gender & $1.2(6)$ \\
& College & $46.8(233)$ \\
& Bachelor's & $41.2(205)$ \\
& Master's & $1.4(7)$
\end{tabular}

Table 3. Measurement items and factor loadings for study variables

\begin{tabular}{|c|c|c|c|}
\hline $\begin{array}{l}\text { Study measures } \\
\text { (References) }\end{array}$ & Measurement items & CFA & \\
\hline Universalism (UNV) & $\begin{array}{l}\text { UNV1: I think it is very important that every person in the world } \\
\text { should be treated equally }\end{array}$ & 0.69 & \\
\hline \multirow[t]{2}{*}{ Bilsky et al. (2011) } & $\begin{array}{l}\text { UNV2: It is important for me to listen to people who are different } \\
\text { from me }\end{array}$ & 0.76 & \\
\hline & UNV3: I strongly believe that people should care for nature & 0.68 & \\
\hline $\begin{array}{l}\text { Openness to change } \\
\text { (OTC) }\end{array}$ & OTC1: I am open to new experiences & 0.85 & \\
\hline \multirow[t]{2}{*}{ Claudy et al. (2015) } & OTC2: I always want to try something new in the market & 0.89 & \\
\hline & OTC3: I every time look for new things & 0.70 & \\
\hline Brand trust (BT) & BT1: I trust natural food brands & 0.93 & \\
\hline \multirow{2}{*}{$\begin{array}{l}\text { Chaudhuri and Holbrook } \\
\text { (2002) }\end{array}$} & BT2: I rely on natural food brands & 0.84 & \\
\hline & BT3: The products of natural food bran & 0.88 & \\
\hline Fake news risks (FNRs) & $\begin{array}{l}\text { FNR1: Fake news about natural food brands made me withdraw } \\
\text { from these products in the past }\end{array}$ & 0.79 & \\
\hline \multirow[t]{3}{*}{ Kumar et al. (2021) } & $\begin{array}{l}\text { FNR2: Fake news about natural food brands made me switch } \\
\text { from one brand to another in the past }\end{array}$ & 0.87 & \\
\hline & $\begin{array}{l}\text { FNR3: Fake news about natural food brands reduced my trust in } \\
\text { the concerned brand in the past }\end{array}$ & 0.92 & \\
\hline & $\begin{array}{l}\text { FNR4: Fake news about natural food brands motivated me to } \\
\text { inform my friends and family to discourage the use of certain } \\
\text { natural food brands in the past }\end{array}$ & 0.79 & \\
\hline System trust (ST) & $\begin{array}{l}\text { ST1: I believe that government control is qualified to certify } \\
\text { natural food products in India }\end{array}$ & $-^{\mathrm{a}}$ & \\
\hline \multirow[t]{2}{*}{$\begin{array}{l}\text { Nuttavuthisit and } \\
\text { Thogersen (2017) }\end{array}$} & $\begin{array}{l}\text { ST2: I have confidence in government-controlled natural food } \\
\text { products }\end{array}$ & $-^{\mathrm{a}}$ & \\
\hline & $\begin{array}{l}\text { ST3: I trust natural food products since I know that government } \\
\text { control is in charge }\end{array}$ & $-^{\mathrm{a}}$ & \\
\hline
\end{tabular}

Note(s): CFAs = confirmatory factor analysis; SEM = structural equation modelling; all loadings are significant below the 0.001 level, and a less than 0.01 difference in loading appears when comparing the CFA

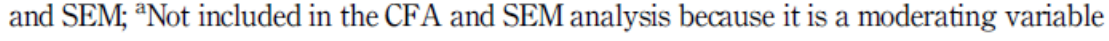


Table 4. Validity and reliability analysis

\begin{tabular}{lcccccccr}
\hline & CR & AVE & MSV & ASV & FNR & UNV & BT & OTC \\
\hline FNR & 0.91 & 0.71 & 0.17 & 0.07 & 0.84 & & & \\
UNV & 0.75 & 0.50 & 0.06 & 0.04 & $-0.19^{* * * *}$ & 0.71 & & \\
BT & 0.91 & 0.78 & 0.17 & 0.07 & $-0.41^{* * *}$ & $0.16^{* * *}$ & 0.88 & \\
OTC & 0.86 & 0.67 & 0.06 & 0.03 & $-0.15^{\text {*** }}$ & $0.24^{\text {**** }}$ & 0.08 & 0.82
\end{tabular}

Note(s): $\mathrm{CR}=$ composite reliability; $\mathrm{AVE}=$ average variance extracted; $\mathrm{MSV}=$ maximum shared; variance; $\mathrm{ASV}=$ average shared variance

Table 5. HTMT analysis

\begin{tabular}{|c|c|c|c|c|}
\hline & UNV & BT & FNR & OTC \\
\hline UNV & & & & \\
\hline BT & 0.15 & & & \\
\hline FNR & 0.18 & 0.41 & & \\
\hline OTC & 0.22 & 0.07 & 0.16 & \\
\hline
\end{tabular}

Figure 2. Results of structural model testing

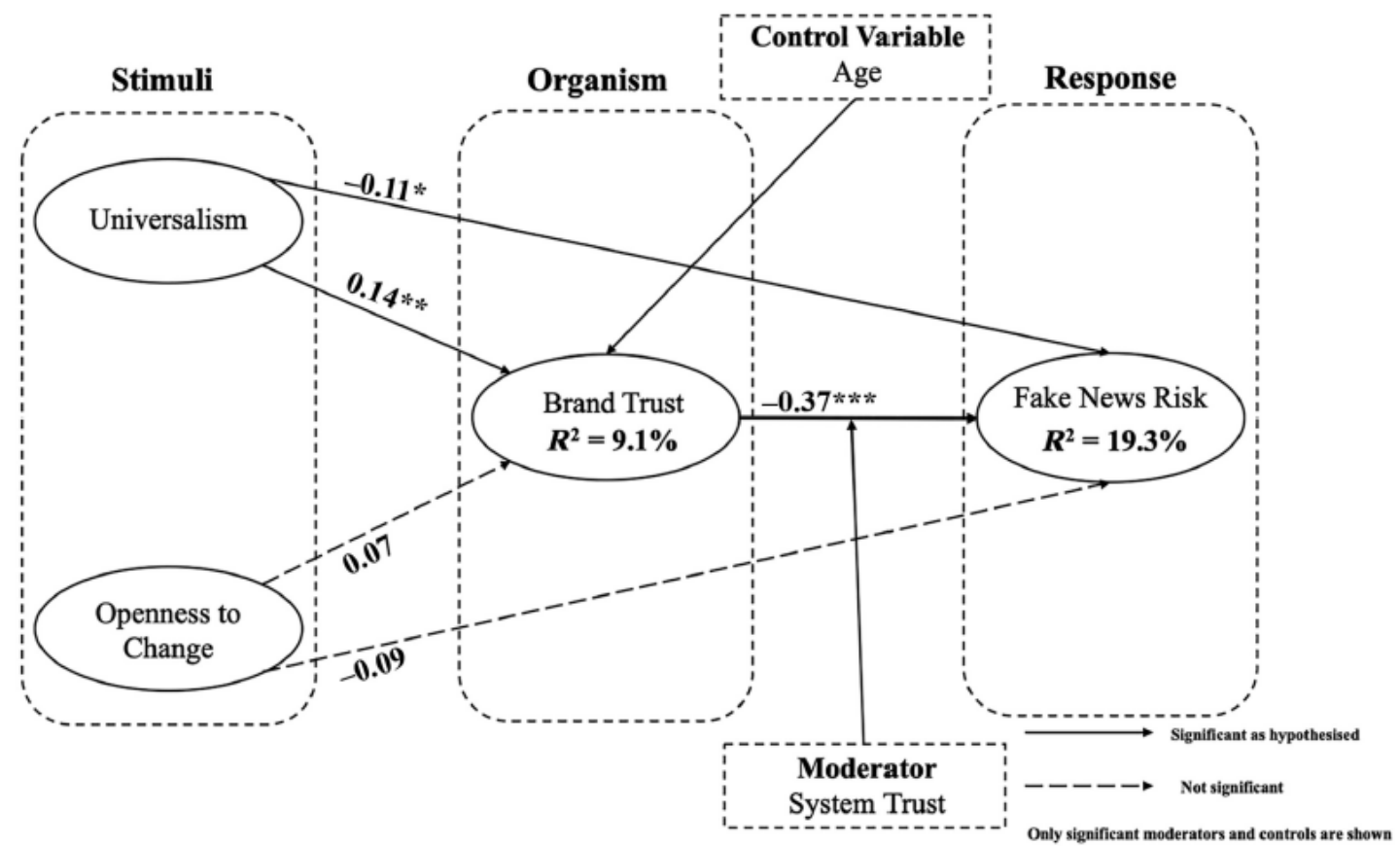

Note(s): ${ }^{*} p<0.05 ;{ }^{* *} p<0.01 ; * * * p<0.001$

\subsection{Structural model and hypotheses testing}

The study tested the proposed hypotheses using structural equation modelling. The model produced satisfactory fit indices $(\chi 2 / \mathrm{df}=1.48, \mathrm{CFI}=0.99, \mathrm{TLI}=0.98, \mathrm{RMSEA}=0.03)$. As illustrated in Figure 2, the results of the structural model analysis showed that universalism was positively associated with brand trust $(\beta=0.14, \mathrm{p}<0.01)$. Thus, H1 was supported. In addition, universalism was negatively associated with fake news risk $(\beta=-0.11, p<0.05)$, thus supporting H3. H5 was also supported as brand trust was negatively associated with 
fake news risks $(\beta=-0.37, \mathrm{p}<0.001)$. However, $\mathrm{H} 2$ and $\mathrm{H} 4$ were not supported because openness to change did not have significant association with either brand trust $(\beta=0.07$, $p>0.05)$ or fake news risk $(\beta=-0.09, p>0.05)$. The model explained $9.1 \%$ of the variance in brand trust and $19.3 \%$ of the variance in fake news risk (refer to Figure 2 and Table 6).

\subsection{Mediation analysis}

We analysed the mediating role of brand trust on the associations between universalism and fake news risk and between openness to change and fake news risk using model 4 in PROCESS macro. The results indicated that brand trust partially mediated the association of universalism and fake news risk due to the presence of significant direct as well as indirect association among them. Hence, H6a is supported. In comparison, brand trust did not mediate the association of openness to change and fake news risk, as evident from the insignificant indirect association (see Table 7). Hence, H6b is not supported.

\subsection{Moderation analysis}

The role of system trust was evaluated as a moderator of the relationship of universalism, openness to change and brand trust with fake news risk (see Table 8) using model 1 in PROCESS macro. The results showed that system trust negatively moderated the relationship between brand trust and fake news risk $(\beta=-0.20, \mathrm{t}=-5.86 ; \mathrm{p}<0.001)$, thus supporting H7c. In other words, brand trust negatively and significantly predicted fake news risk when consumers exhibited moderate or strong trust in the government's control system for natural food brands (see Figure 3). However, this negative relationship was not significant when consumers exhibited weak system trust. In contrast, system trust moderated neither the relationship between universalism and fake news risk $(p=0.34)$ nor the relationship between openness to change and fake news risk $(p=0.20)$. Thus, H7a and H7b were not supported.

Table 6. Results of hypotheses testing

\begin{tabular}{llrcc}
\hline Hypothesis & Path & $\beta$ & $p$ & Support \\
\hline H1 & UNV $\rightarrow$ BT & 0.14 & $<0.01$ & Yes \\
H2 & OTC $\rightarrow$ BT & 0.07 & $>0.05$ & No \\
H3 & UNV $\rightarrow$ FNR & -0.11 & $<0.05$ & Yes \\
H4 & OTC $\rightarrow$ FNR & -0.09 & $>0.05$ & No \\
H5 & BT $\rightarrow$ FNR & -0.37 & $<0.001$ & Yes \\
\hline
\end{tabular}


Table 7. Results of mediation analysis of brand trust

\begin{tabular}{|c|c|c|c|c|c|c|}
\hline $\mathrm{OTC} \rightarrow \mathrm{BT} \rightarrow \mathrm{FNR}$ & $\beta$ & se & $t$ & $p$ & LLCI & ULCI \\
\hline $\mathrm{OTC} \rightarrow \mathrm{BT}$ & 0.07 & 0.05 & 1.35 & 0.18 & -0.0298 & 0.1611 \\
\hline $\mathrm{OTC} \rightarrow \mathrm{FNR}$ & -0.11 & 0.04 & -2.81 & 0.01 & -0.1946 & -0.0343 \\
\hline $\mathrm{BT} \rightarrow \mathrm{FNR}$ & -0.33 & 0.04 & -8.86 & 0.00 & -0.4075 & -0.2596 \\
\hline Total effect of OTC $\rightarrow$ FNR & -0.14 & 0.04 & -3.11 & 0.00 & -0.2223 & -0.0503 \\
\hline \multirow[t]{2}{*}{$\mathrm{UNV} \rightarrow \mathrm{BT} \rightarrow \mathrm{FNR}$} & & & & & & \\
\hline & $\beta$ & se & $t$ & $p$ & LLCI & ULCI \\
\hline $\mathrm{UNV} \rightarrow \mathrm{BT}$ & 0.28 & 0.10 & 2.81 & 0.01 & 0.0838 & 0.4727 \\
\hline $\mathrm{UNV} \rightarrow \mathrm{FNR}$ & -0.22 & 0.08 & -2.66 & 0.01 & -0.3893 & -0.0585 \\
\hline $\mathrm{BT} \rightarrow \mathrm{FNR}$ & -0.33 & 0.04 & -8.64 & 0.00 & -4.018 & -0.2529 \\
\hline Total effect of OTC $\rightarrow$ FNR & -0.32 & 0.09 & -3.52 & 0.00 & -0.4909 & -0.1392 \\
\hline \multirow[t]{2}{*}{ Indirect effect } & & & & & & \\
\hline & Effect & & se & \multicolumn{2}{|c|}{ LLCI } & ULCI \\
\hline $\mathrm{OTC} \rightarrow \mathrm{BT} \rightarrow \mathrm{FNR}$ & -0.02 & & 0.02 & \multicolumn{2}{|c|}{-0.0578} & 0.0112 \\
\hline $\mathrm{UNV} \rightarrow \mathrm{BT} \rightarrow \mathrm{FNR}$ & -0.09 & & 0.03 & \multicolumn{2}{|c|}{-0.1585} & -0.0335 \\
\hline
\end{tabular}

Table 8. Results of moderation analysis of system trust

\begin{tabular}{lrrrrrl}
\hline & \multicolumn{1}{c}{$\boldsymbol{c}$} & \multicolumn{1}{c}{$\boldsymbol{c}$} & \multicolumn{1}{c}{ LLCI } & ULCI & Moderation? \\
\hline OTC $\rightarrow$ FNR & 0.05 & 1.29 & 0.20 & -0.0243 & 0.1177 & No \\
UNV $\rightarrow$ FNR & 0.09 & 0.96 & 0.34 & -0.0940 & 0.2732 & No \\
BT $\rightarrow$ FNR & -0.20 & -5.86 & 0.00 & -0.2699 & -0.1343 & Yes \\
\hline
\end{tabular}

Figure 3. The moderating role of system trust in the relationship between brand trust and fake news risks

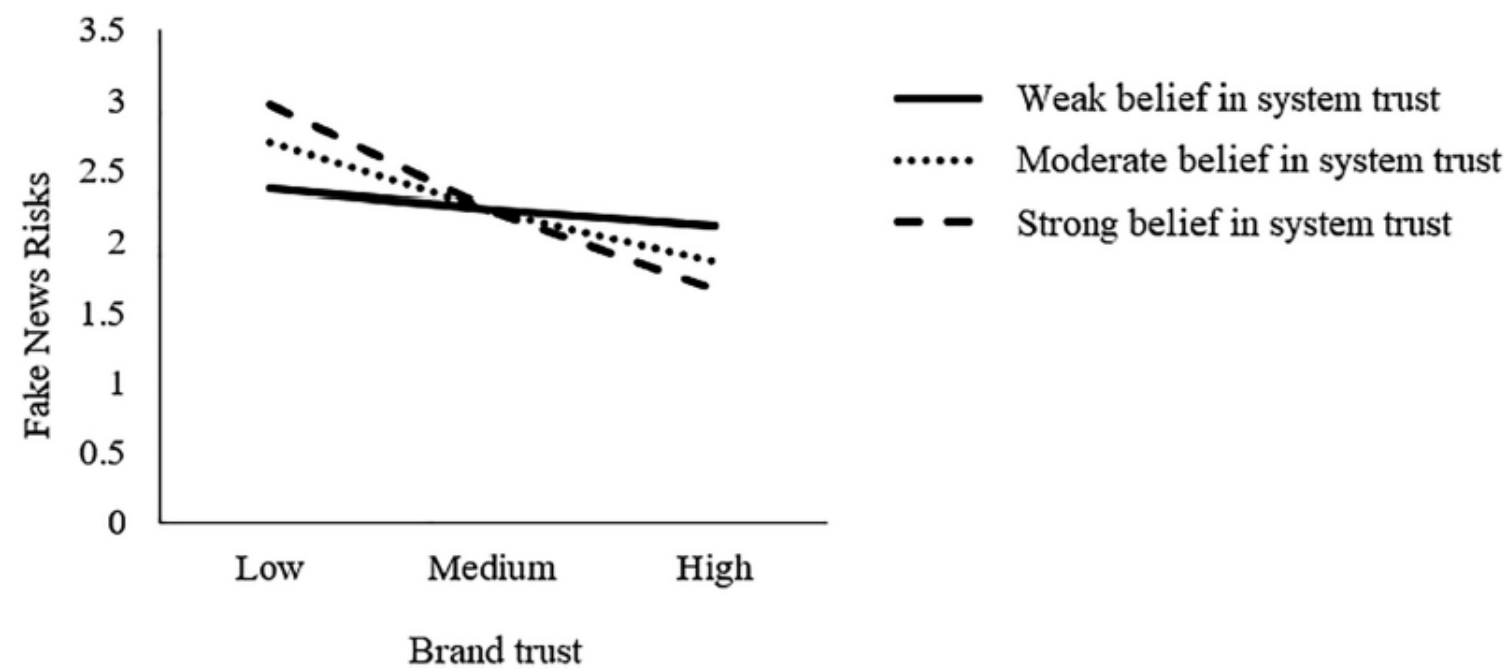




\section{Discussion}

The present study examined the potential association of universalism and openness to change with brand trust and fake news risk in the context of natural food brands. At the same time, the possibility of association between brand trust and fake news risk was also examined. In addition, the study considered the mediation effect of brand trust on the association of the two values with fake news risk, and the moderation effect of system trust on the same associations. Furthermore, the moderation effect of system trust on the association of brand trust and fake news risk was examined. Finally, the two dependent variables were controlled for the confounding effect of age and gender.

The results of the analysis of structural model indicate that universalism is positively associated with brand trust and fake news risk (H1). In other words, in the context of natural food brands, consumers who are guided by universalism as a value tend to have higher levels of brand trust. Such consumers are, moreover, more resilient against fake news claims regarding natural food brands. These findings align with the previous literature regarding the guiding role of universalism in natural food consumption (Thøgersen and Zhou, 2017; Thøgersen et al., 2015; Aertsens et al., 2009). Because natural foods are considered to healthier, not genetically modified (non-GMO) (Chambers and Castro, 2018), fresher and purer (Rozin et al., 2012) and morally superior to consume than conventional foods (Rozin et al., 2004), the supported hypotheses rationally justify consumers' preference for natural food brands. The present study also observed a statistically significant negative association between universalism and fake news risk (H3), which implies that consumers with high value of universalism respond to fake news about natural food brands by withdrawing completely from the use of these products or switching from the brand about which the news is circulating. In addition, consumers who believe that human beings should care for nature not only lose their own trust in the natural food brands about which the fake news is circulating but also discourage friends and family from using these brands. This finding is consistent with our anticipating based on the prior extended literature (e.g. Farrell et al., 2019; Thøgersen et al., 2017).

Unexpectedly, our results support neither the association between openness to change and brand trust (H2) nor the association between openness to change and fake news risk (H4). A possible reason could be that openness to change causes consumers to constantly seek new brand experiences, which means that natural food brands alone may not satisfy their need for novel experiences. For example, a study by Mainardes et al. (2017) suggested that in developing markets, consumers who are more open to change are more inclined towards fast food and industrial food rather than natural food. Further, openness to change shares elements of hedonism that are negatively associated with natural food consumption (Caracciolo et al., 2016). In this regard, Indian participants in the current study were not able to evaluate their level of openness to change towards natural food brands, which resulted in non-significant findings in all of the hypotheses that related to openness to change, including the moderating effect of system trust on openness to change.

Our results do support a significant negative relationship between brand trust and fake news risk (H5), which demonstrates that when consumers trust a natural food brand, they are less likely to act on (or, in the first place, believe) fake news regarding the brand. Because brand trust is the most important parameter in defending brand value against fake news risk 
(Visentin et al., 2019), brand managers should remain alert for and protect their brands against media that are likely to distribute fake news regarding their natural food products. We also analysed the mediating role of brand trust on the association between the selected basic human values - universalism and openness to change - and fake news risk (H6a-b). We observed only partial mediation effect of brand trust on the association between universalism and fake news risk, which indicates that consumers who are driven by universalism remain strongly resilient against the risks of fake news. In the present study, fake news had very little effect on Indian participants' trust in a given brand because they were already convinced about the value of natural food brands and those brands' positive effect on the environment, health and society at large. This finding is consistent with Khare and Pandey's (2017) research, which examined green self-identity and the influence of Indian organic food on consumers' perceived trust.

We further observed a moderating effect for system trust on the association between of both values and brand trust with fake news risk (H7a-c). This implies that consumers with a moderate or strong belief in the government's authority, certifications, rules and regulatory bodies will be more inclined to trust natural food brands and be more resilient against fake news. This finding aligns with Pennington et al.'s (2003) work, which found that system trust assures consumers of a product's safety by reducing uncertainty through laws and regulations, certificating bodies and legal norms.

\section{Conclusion}

The increasing consumption of natural food brands is unsurprising, especially during the COVID-19 pandemic, which has impelled consumers to seek safer food options. Because natural food is already considered healthier, the demand for it will continue to grow exponentially. Despite the potential the area holds, academic inquiry into this area remains limited. The extant research regarding consumer behaviour in the context of natural food brands likewise exhibits significant gaps, especially regarding the effects on brand trust of consumers' exposure to uncertain events (such as fake news risk) related to natural food brands. By utilising the theory of basic human values (Schwartz, 1992) and the SOR framework, our study offers significant contributions and entails useful theoretical and practical implications. With regard to RQ1, enquiring about the association of the two values with brand trust and fake news risk in the context of natural food brands, the present study found that universalism has a positive relationship with brand trust, whereas openness to change has no association. Regarding RQ2, raising query about the potential nature of association between brand trust and fake news risk, the results confirmed a negative association between the two. Coming to RQ3, conceptualizing the role of brand trust as an intervening mechanism between the two values and fake news risk, the results confirmed that brand trust partially mediates the association between universalism and fake news risk only. Finally, the results for RQ4, contemplating the moderation effect of system trust on the association of the two values and brand trust with fake news risk, findings confirmed that system trust moderates only the association of brand trust with fake news risk. These findings, in turn, entail significant implications for policymakers, natural food marketers and future researchers, as discussed below. 


\subsection{Theoretical implications}

The study offers four theoretical contributions. First, the tested model contributes to theoretical efforts to explain consumer behaviour towards natural food (1) by adapting wellacknowledged and widely accepted theories to understand consumers' behaviour towards natural food brands and (2) by analysing the contemporary threat of fake news regarding natural food brands, which consumers already find inherently suspicious due to their high price and unclear origins.

Second, the study confirms previous findings identifying universalism as a dominant value that guides consumers to adopt more environmentally friendly and safer food options (Thøgersen, 2007, 2017). The study also suggests that universalism is positively associated with brand trust and that concern for people's well-being and the environment does lead to brand trust. However, another value dimension, openness to change, was negatively associated with brand trust and with fake news risk.

Third, the study addresses some of the limitations of previous studies by focussing on natural food brands. Bobo and Chakraborty (2016) suggested that natural food is often confused with other food products, such as locally grown foods. Asioli et al. (2017) stated that cultural differences significantly affect consumers' perceptions about food and their associated consumption behaviour in emerging markets. The present study, which was conducted in one of the fastest-growing emerging markets - India, associated the fake news risk that natural food brands encounter with the resultant consumer conative actions. Studies by Carocho et al. (2015) and Mathiot (2018) revealed that consumers experience "link loss" with natural foods. In other words, they are inherently suspicious of such foods' origins and production systems, and these suspicions leave natural food brands more susceptible to fake news risk. The present study fills this gap, suggesting that consumers who exhibit higher levels of universalism are less likely to believe fake news regarding natural food brands.

Fourth, this study contributes to ongoing theoretical efforts by proposing system trust as a moderator influencing the associations between basic human values (universalism and openness to change) and fake news risk and between brand trust and fake news risk. While previous studies have reported that consumers with lower levels of system trust tend to be less inclined to buy natural food products (Nuttavuthisit and Thøgersen, 2017), this study advances the discussion on consumers' reactions towards fake news. We found that system trust moderated the relationship between brand trust and fake news risk, which suggests that the level of consumer trust (i.e. a moderate or strong belief) in the government's control system will eventually minimise fake news risk towards natural food brands.

\subsection{Practical implications}

The present study offers three implications for practice. First, because this study revealed that universalism affects both brand trust and fake news risk, brand managers should utilise universalism values in their promotion of natural food products. Emphasising, in particular, the ways in which their products promote the well-being of all people and protect the environment has the potential to significantly impact natural food consumption. In addition, Indian culture tends to prioritise the knowledge of Ayurveda and the value of naturally grown herbal medicines (Jaiswal and Williams, 2017). In this context, natural food brands can increase consumer trust by positioning their products as plant-based and highlighting each 
product's journey from the source to its final packaging and quality checks. The increased interest and demand for natural immunity-enhancing products during the COVID-19 pandemic, moreover, makes it even more important for brand managers to focus on the aspects of their products that promote "well-being for all". In doing so, however, brand managers and marketers must also exercise caution to avoid highlighting any aspects of such products that consumers might perceive negatively. For example, natural foods that are procured in an unsustainable manner or that utilise plastic packaging would run counter to the tenets of universalism.

Second, our study revealed that consumers with higher levels of universalism tended not to believe the fake news they encountered regarding natural food brands. Because universalism was also positively associated with brand trust, we recommend that brands openly discuss any fake news that targets their products on any social media platforms that consumers actively use. When this narrative repeats - i.e. when a brand addresses false claims lodged against it, it will act as a stimulus for consumers to recognise that the brand is responsive and concerned about their well-being and interests. Thus, we recommend that brands consistently acknowledge and provide information to refute fake news. In the current information-laden environment, it is essential for brands to serve as the first point of contact for consumers, to listen to their opinions and thus to co-create their experiences in a way that enhances brand trust.

Finally, our study found that brand trust is positively associated with fake news risk. To further increase consumers' brand trust, brands must (1) secure endorsements from health professionals for their natural food products and (2) produce informative content about the benefits of such products, especially regarding ethical farming methods and products' nutrient profiles. During the COVID-19 pandemic, myriad natural food brands have obtained endorsements from health professionals. Such endorsements enhance the credibility of the brands' claims. Moreover, brands can establish trust by inviting randomly selected consumers to visit their manufacturing units while following COVID-19 protocols. Where physical limitations preclude such visits, brands can still impart some control to consumers by sharing real-time updates about their products' histories and procurement processes.

\subsection{Limitations and future research directions}

Despite its contributions, the present study does entail some limitations. First, the data collection took place in only one emerging country; thus, the study's findings may not be generalisable to other emerging markets with different cultural contexts. Nevertheless, the sample size was adequate, and the sampling method was selected to minimise data biases. Future studies can strengthen our efforts by conducting replication studies in culturally diverse emerging markets that operate under different governing systems. Further, future researches could compare and contrast between the potential and actual buyers of natural foods, including their pre- and post-purchase behaviours. Moreover, future research should consider the possible influence of cultural dimensions (collectivist versus individualistic) on the consumption of natural food products. Second, buyers of natural food comprised this study's respondents, but the study did not consider these buyers' post-purchase behaviours or customer life cycles. Farrell et al. (2019) found that values affect consumers' information sharing decisions. In fact, their study explained that consumers weigh their own values more heavily than the truth of a message when deciding whether or not to share any piece of brand related 
information. However, value systems drive complex behaviours, and future research should conduct comparison studies of groups of values and sub-values and observe the moderating effects of self-congruence on the relationships between consumers' basic human values and the fake news risk of natural food brands. Third, the present study considered natural foods as an overarching category, which limits the generalisability of its findings. Future researchers might, therefore, explore specific product categories not only of foods but also of herbs used as alternative medicine. Specific food categories provide a category-level perspective capable of considering consumer involvement and the time taken until an actual purchase. Another interesting line of enquiry might evaluate whether consumers are category loyal (only to a natural food category) or brand loyal (only to a natural food brand). Finally, the present study explored brand trust and fake news risk associated with natural food products. Future studies can extend our work by taking a phenomenological approach, which will allow future researchers to understand the trust perspective of consumers who have consistently purchased only natural brand foods or who have grown the same.

\section{References}

Aertsens, J., Verbeke, W., Mondelaers, K. and Huylenbroeck, G.V. (2009), "Personal determinants of organic food consumption: a review", British Food Journal, Vol. 111 No. 10, pp. 1140-1167, doi: 10.1108/00070700910992961.

Asioli, D., Aschemann-Witzel, J., Caputo, V., Vecchio, R., Annunziata, A., Næs, T. and Varela, P. (2017), "Making sense of the 'clean label' trends: a review of consumer food choice behavior and discussion of industry implications", Food Research International, Vol. 99, pp. 58-71, doi: 10.1016/j.foodres.2017.07.022.

Backstrom, A., Pirttil€a-Backman, A.-M. and Tuorila, H. (2004), "Willingness to try new foods as predicted by social representations and attitude and trait scales", Appetite, Vol. 43 No. 1, pp. 75-83, doi: 10.1016/j.appet.2004.03.004.

Bilsky, W., Janik, M. and Schwartz, S.H. (2011), "The structural organization of human valuesevidence from three rounds of the European Social Survey (ESS)", Journal of Cross-Cultural Psychology, Vol. 42 No. 5, pp. 759-776.

Bobo, J. and Chakraborty, S. (2016), "Predictably irrational consumer food preferences", European Journal of Risk Regulation, Vol. 73, pp. 604-609, doi: 10.1017/S1867299X00006759.

Bronstein, M.V., Pennycook, G., Bear, A., Rand, D.G. and Cannon, T.D. (2019), "Belief in fake news is associated with delusionality, dogmatism, religious fundamentalism, and reduced analytic thinking", Journal of Applied Research in Memory and Cognition, Vol. 8 No. 1, pp. 108-117, doi:10.1016/j.jarmac.2018.09.005.

Caracciolo, F., Cicia, G., Del Giudice, T., Cembalo, L., Krystallis, A., Grunert, K.G. and Lombardi, P. (2016), "Human values and preferences for cleaner livestock production", Journal of Cleaner Production, Vol. 112, pp. 121-130, doi: 10.1016/j.jclepro.2015.06.045.

Carocho, M., Morales, P. and Ferreira, I.C. (2015), “Natural food additives: Quo vadis?”, Trends in Food Science and Technology, Vol. 45 No. 2, pp. 284-295, doi: 10.1016/j.tifs.2015.06.007.

Casalo, L.V., Flavian, C. and Guinal 1u, M. (2007), "The influence of satisfaction, perceived reputation and trust on a consumer's commitment to a website", Journal of Marketing Communications, Vol. 13 No. 1, pp. 1-17, doi: 10.1080/13527260600951633.

Chambers, E. and Castro, M. (2018), "What is 'natural'? Consumer responses to selected ingredients", Foods, Vol. 7 No. 4, p. 65, doi: 10.3390/foods 7040065.

Chambers, E., Tran, T. and Chambers IV, E. (2019), "Natural: a $\$ 75$ billion word with no definitionWhy not?”, Journal of Sensory Studies, Vol. 34 No. 4, e12501, doi: 10.1111/joss.12501. 
Chandna, H. (2020), “Ayurveda, FMCG, VOID, controversy-Baba Ramdev and the Patanjali school of marketing", The Print, available at: https://theprint.in/opinion/newsmaker-of-the-week/ayurvedafmcg-covid-controversy-baba-ramdev-and-the-patanjali-school-of-marketing/449625/ (accessed 20 June 2020).

Chaudhuri, A. and Holbrook, M.B. (2001), "The chain of effects from brand trust and brand affect to brand performance: the role of brand loyalty", Journal of Marketing, Vol. 65 No. 2, pp. 81-93, doi:10.1509/jmkg.65.2.81.18255.

Chaudhuri, A. and Holbrook, M.B. (2002), "Product-class effects on brand commitment and brand outcomes: the role of brand trust and brand affect", Journal of Brand Management, Vol. 10 No. 1, pp. 33-58, doi: 10.1057/palgrave.bm.2540100.

Chen, Z.F. and Cheng, Y. (2019), "Consumer response to fake news about brands on social media: the effects of self-efficacy, media trust, and persuasion knowledge on brand trust", Journal of Product and Brand Management, Vol. 29 No. 2, pp. 188-198, doi: 10.1108/JPBM-12-2018-2145.

Claudy, M.C., Garcia, R. and O’Driscoll, A. (2015), "Consumer resistance to innovation-a behavioral reasoning perspective", Journal of the Academy of Marketing Science, Vol. 43 No. 4, pp. 528-544.

de Jonge, J., Van Trijp, J.C.M., van der Lans, I.A., Renes, R.J. and Frewer, L.J. (2008), "How trust in institutions and organizations builds general consumer confidence in the safety of food: a decomposition of effects", Appetite, Vol. 51 No. 2, pp. 311-317.

De Pelsmacker, P., Moons, I. and Barvarossa, C. (2016), "A self-identity driven model of electric car adoption and the moderating role of personal values", International Conference Marketing Trends, pp. 1-16, available at: https://en.calameo.com/read/00031243452d8aff06072.

de Regt, A., Montecchi, M. and Ferguson, S.L. (2019), "A false image of health: how fake news and pseudo-facts spread in the health and beauty industry", Journal of Product and Brand Management, Vol. 29 No. 2, pp. 168-179, doi: 10.1108/JPBM-12-2018-2180.

Dhir, A., Chen, G.M. and Chen, S. (2017), "Why do we tag photographs on Facebook? Proposing a new gratifications scale”, New Media and Society, Vol. 19 No. 4, pp. 502-521, doi: $10.1177 / 1461444815611062$.

Dhir, A., Yossatorn, Y., Kaur, P. and Chen, S. (2018), "Online social media fatigue and psychological well-being - a study of compulsive use, fear of missing out, fatigue, anxiety and depression", International Journal of Information Management, Vol. 40, pp. 141-152, doi: 10.1016/j.ijinfomgt.2018.01.012.

Expert Market Research (2020), "India organic food market report and Forecast 2021-2026", available at: https://www.expertmarketresearch.com/reports/india-organic-food-market (accessed 20 April 2021).

Farrell, T., Piccolo, L., Perfumi, S.C., Alani, H. and Mensio, M. (2019), "Understanding the role of human values in the spread of misinformation", Conference for Truth and Trust Online.

Field, A. (2018), PR and the Problem of Truth Decay: It's a Matter of Trust, Institute for Public Relations, available at: https://instituteforpr.org/pr-and-the-problem-of-truth-decay-its-a-matteroftrust/ (accessed 15 March 2020).

Flostrand, A., Pitt, L. and Kietzmann, J. (2020), "Fake news and brand management: a Delphi study of impact, vulnerability and mitigation", Journal of Product and Brand Management, Vol. 29 No. 2, pp. 246-254, doi: 10.1108/JPBM-12-2018-2156.

Fornell, C. and Larcker, D.F. (1981), "Evaluating structural equation models with unobservable variables and measurement error", Journal of Marketing Research, Vol. 18 No. 1, pp. 39-50, doi: $10.3106 / 235.38$.

Fournier, S. (1998), "Consumers and their brands: developing relationship theory in consumer research", Journal of Consumer Research, Vol. 24 No. 4, pp. 343-373. 
Fritzsche, D. and Oz, E. (2007), "Personal values' influence on the ethical dimension of decision making", Journal of Business Ethics, Vol. 75 No. 4, pp. 335-343.

Gautam, A. (2018), "Are Patanjali products really banned in Qatar due to excessive use of chemicals in their products?", Fact Hunt, available at: https:/facthunt.in/posts/243/Are-Patanjali-productsreallybanned-in-Qatar-due-to-excessive-use-of-chemicals-in-their-products (accessed 20 March 2020).

Gupta, A. and Arora, N. (2017), "Consumer adoption of m-banking: a behavioral reasoning theory perspective", International Journal of Bank Marketing, Vol. 35 No. 4, pp. 733-747, doi: 10.1108/IJBM-11-2016-0162.

Gurviez, P. and Korchia, M. (2002), "Proposition d'une echelle de mesure multidimensionnelle de la confiance dans la marque", Recherche et Applications en Marketing (French Edition), Vol. 17 No. 3, pp. 41-61.

Hair, J.F., Black, W.C., Babin, B.J., Anderson, R.E. and Tatham, R.L. (2014), "Pearson new international edition", Multivariate Data Analysis, 7th ed., Pearson Education, Harlow, Essex.

Hansen, T., Sørensen, M.I. and Eriksen, M.L.R. (2018), "How the interplay between consumer motivations and values influences organic food identity and behaviour", Food Policy, Vol. 74, pp. 39-52, doi: 10.1016/j.foodpol.2017.11.003.

Hargreaves, S. (2008), Apple's Stock Hit by Web Rumor-Online Report that CEO Steve Jobs Suffered a Heart Attack Was False. SEC Said to Be Investigating, CNNMoney.Com, available at: https://money.cnn.com/2008/10/03/technology/apple/ (accessed 10 January 2020).

Henseler, J., Ringle, C.M. and Sarstedt, M. (2015), “A new criterion for assessing discriminant validity in variance-based structural equation modelling", Journal of the Academy of Marketing Science, Vol. 43 No. 1, pp. 115-135, doi: 10.1007/s11747-014-0403-8.

Hobbs, J.E. and Goddard, E. (2015), "Consumers and trust”, Food Policy, Vol. 52, pp. 71-74.

Jaiswal, Y.S. and Williams, L.L. (2017), "A glimpse of Ayurveda-The forgotten history and principles of Indian traditional medicine", Journal of Traditional and Complementary Medicine, Vol. 7 No. 1, pp. 50-53, doi: 10.1016/j.jtcme.2016.02.002.

Kahle, L.R., Beatty, S.E. and Homer, P. (1986), "Alternative measurement approaches to consumer values: the list of values (LOV) and values and life style (VALS)", Journal of Consumer Research, Vol. 13 No. 3, pp. 405-409.

Kang, H., Bae, K., Zhang, S. and Sundar, S.S. (2011), "Source cues in online news: is the proximate source more powerful than distal sources?", Journalism and Mass Communication Quarterly, Vol. 88 No. 4, pp. 719-736, doi: 10.1177/107769901108800403.

Khare, A. and Pandey, S. (2017), "Role of green self-identity and peer influence in fostering trust towards organic food retailers", International Journal of Retail and Distribution Management, Vol. 45 No. 9, pp. 969-990, doi: 10.1108/IJRDM-07-2016-0109.

Kim, E.J., Kim, S.H. and Lee, Y.K. (2019), "The effects of brand hearsay on brand trust and brand attitudes", Journal of Hospitality Marketing and Management, Vol. 28 No. 7, pp. 765-784.

Kim, M.J., Lee, C.K. and Jung, T. (2020), "Exploring consumer behavior in virtual reality tourism using an extended stimulus-organism-response model", Journal of Travel Research, Vol. 59 No. 1, pp. 69-89, doi: 10.1177/0047287518818915.

Konuk, F.A. (2018), "The role of store image, perceived quality, trust and perceived value in predicting consumers' purchase intentions towards organic private label food", Journal of Retailing and Consumer Services, Vol. 43, pp. 304-310, doi: 10.1016/j.jretconser.2018.04.011.

Kumar, S., Dhir, A., Talwar, S., Chakraborty, D. and Kaur, P. (2021a), "What drives brand love for natural products? The moderating role of household size", Journal of Retailing and Consumer Services, Vol. 58, 102329, doi: 10.1016/j.jretconser.2020.102329. 
Kumar, S., Talwar, S., Krishnan, S., Kaur, P. and Dhir, A. (2021b), "Purchasing natural personal care products in the era of fake news? The moderation effect of brand trust", Journal of Retailing and Consumer Services, Vol. 63, 102668.

Lassoued, R. and Hobbs, J.E. (2015), "Consumer confidence in credence attributes: the role of brand trust”, Food Policy, Vol. 52, pp. 99-107, doi: 10.1016/j.foodpol.2014.12.003.

Lea, E. and Worsley, T. (2005), “Australians' organic food beliefs, demographics and values”, British Food Journal, Vol. 107 No. 11, pp. 855-869, doi: 10.1108/00070700510629797.

Mainardes, E.W., de Araujo, D.V.B., Lasso, S. and Andrade, D.M. (2017), "Influences on the intention to buy organic food in an emerging market", Marketing Intelligence and Planning, Vol. 35 No. 7, pp. 858-876, doi: 10.1108/MIP-04-2017-0067.

Mathiot, L. (2018), "From how consumers categorize natural food to their buying methods: a comparative study between France and Israel", Review of Agricultural, Food and Environmental Studies, Vol. 99 No. 1, pp. 57-76, doi: 10.1007/s41130-017-0056-3.

Mehrabian, A. and Russell, J.A. (1974), An Approach to Environmental Psychology, The MIT Press, Cambridge, MA.

Michel, F. and Siegrist, M. (2019), "How should importance of naturalness be measured? A comparison of different scales", Appetite, Vol. 140, pp. 298-304, doi: 10.1016/j.appet.2019.05.019.

Migliore, G., Borrello, M., Lombardi, A. and Schifani, G. (2018), “Consumers' willingness to pay for natural food: evidence from an artefactual field experiment", Agricultural and Food Economics, Vol. 6 No. 1, p. 21, doi: 10.1186/s40100-018-0117-1.

Mills, A.J. and Robson, K. (2019), "Brand management in the era of fake news: narrative response as a strategy to insulate brand value", Journal of Product and Brand Management, Vol. 29 No. 2, pp. 159-167, doi: 10.1108/JPBM-12-2018-2150.

Molinillo, S., Vidal-Branco, M. and Japutra, A. (2020), "Understanding the drivers of organic foods purchasing of millennials: evidence from Brazil and Spain", Journal of Retailing and Consumer Services, Vol. 52, 101926, doi: 10.1016/j.jretconser.2019.101926.

Moscato, E.M. and Machin, J.E. (2018), "Mother natural: motivations and associations for consuming natural foods", Appetite, Vol. 121, pp. 18-28, doi: 10.1016/j.appet.2017.10.031/.

Nasir, V.A. and Karakaya, F. (2014), “Consumer segments in organic foods market”, Journal of Consumer Marketing, Vol. 31 No. 4, pp. 263-277, doi: 10.1108/JCM-01-2014-0845.

Ngo, H.M., Liu, R., Moritaka, M. and Fukuda, S. (2020a), "Effects of industry-level factors, brand credibility and brand reputation on brand trust in safe food: evidence from the safe vegetable sector in Vietnam", British Food Journal, Vol. 122 No. 9, pp. 2993-3007.

Ngo, H.M., Liu, R., Moritaka, M. and Fukuda, S. (2020b), "Urban consumer trust in safe vegetables in Vietnam: the role of brand trust and the impact of consumer worry about vegetable safety", Food Control, Vol. 108, 106856.

Nuttavuthisit, K. and Thøgersen, J. (2017), "The importance of consumer trust for the emergence of a market for green products: the case of organic food”, Journal of Business Ethics, Vol. 140 No. 2, pp. 323-337, doi: 10.1007/s10551-015-2690-5.

Ouyang, Y., Behnke, C., Almanza, B. and Ghiselli, R. (2018), "The influence of food aromas on restaurant consumer emotions, perceptions, and purchases", Journal of Hospitality Marketing and Management, Vol. 27 No. 4, pp. 405-423, doi: 10.1080/19368623.2017.1374225.

Pennington, R., Wilcox, H.D. and Grover, V. (2003), "The role of system trust in business-to-consumer transactions", Journal of Management Information Systems, Vol. 20 No. 3, pp. 197-226, doi: 10.1080/07421222.2003.11045777. 
Pennycook, G. and Rand, D.G. (2019), "Lazy, not biased: susceptibility to partisan fake news is better explained by lack of reasoning than by motivated reasoning", Cognition, Vol. 188, pp. 39-50, doi: 10.1016/j.cognition.2018.06.011.

Peterson, M. (2020), "A high-speed world with fake news: brand managers take warning", Journal of Product and Brand Management, Vol. 29 No. 2, pp. 234-245, doi: 10.1108/JPBM-12-2018-2163.

Podsakoff, P.M., MacKenzie, S.B., Lee, J.Y. and Podsakoff, N.P. (2003), "Common method biases in behavioral research: a critical review of the literature and recommended remedies", Journal of Applied Psychology, Vol. 88 No. 5, pp. 879-903, doi: 10.1037/0021-9010.88.5.879.

Rajagopal, D. (2019), "Tatas battle misinformation campaign against salt brand", The Economic Times, available at: https://economictimes.indiatimes.com/industry/cons-products/fmcg/tatasbattlemisinformation-campaign-against-salt-brand/articleshow/70049673.cms?from5mdr (accessed 16 March 2021).

Ramasamy, S., Dara Singh, K.S., Amran, A. and Nejati, M. (2019), "Linking human values to consumer CSR perception: the moderating role of consumer skepticism", Corporate Social Responsibility and Environmental Management, Vol. 27 No. 4, pp. 1958-1971.

Rao, J.N. (2019), "False allegations of toxins and harmful chemicals in India's widely sold commercial salt brands", Alt News, available at: https://www.altnews.in/false-allegations-of-toxins-andharmfulchemicals-in-indias-widely-sold-commercial-salt-brands/ (accessed 16 March 2021).

Roman, S., Sanchez-Siles, L.M. and Siegrist, M. (2017), “The importance of food naturalness for consumers: results of a systematic review", Trends in Food Science and Technology, Vol. 67, pp. 44-57, doi: 10.1016/j.tifs.2017.06.010.

Rozin, P., Spranca, M., Krieger, Z., Neuhaus, R., Surillo, D., Swerdlin, A. and Wood, K. (2004), "Preference for natural: instrumental and ideational/moral motivations, and the contrast between foods and medicines", Appetite, Vol. 43 No. 2, pp. 147-154, doi: 10.1016/j.appet.2004.03.005.

Rozin, P., Fischler, C. and Shields-Argel es, C. (2012), "European and American perspectives on the meaning of natural", Appetite, Vol. 59 No. 2, pp. 448-455, doi: 10.1016/j.appet.2012.06.001.

Sakdiyakorn, M., Golubovskaya, M. and Solnet, D. (2021), "Understanding Generation Z through collective consciousness: impacts for hospitality work and employment", International Journal of Hospitality Management, Vol. 94, 102822.

Sassatelli, R. and Scott, A. (2001), "Novel food, new markets and trust regimes: responses to the erosion of consumers' confidence in Austria, Italy and the UK", European Societies, Vol. 3 No. 2, pp. 213-244, doi: 10.1080/146166901200543339.

Schwartz, S.H. (1992), "Universals in the content and structure of values: theoretical advances and empirical tests in 20 countries", Advances in Experimental Social Psychology, Vol. 25 No. 1, pp. 165, doi: 10.1016/S0065-2601(08)60281-6.

Schwartz, S.H. and Sagiv, L. (1995), "Identifying culture-specifics in the content and structure of values", Journal of Cross-Cultural Psychology, Vol. 26 No. 1, pp. 92-116, doi: 10.1177/0022022195261007.

Sepasi, S., Rexhepi, G. and Rahdari, A. (2021), “The changing prospects of corporate social responsibility in the decade of action: do personal values matter?", Corporate Social Responsibility and Environmental Management, Vol. 28 No. 1, pp. 138-152.

Singh, N. (2018), "Delhi HC does not find Kurkure 'plastic' jokes funny, orders social media giants to erase them", The Print, available at: https://theprint.in/india/governance/delhi-hc-does-notfindkurkure-plastic-jokes-funny-orders-social-media-giants-to-erase-them/89049/ (accessed 27 November 2020). 
Sullivan, L. (2019), “Study finds 'fake news’ has real cost: \$78 billion”, MediaPost, available at: https://www.mediapost.com/publications/article/343603/study-finds-fake-news-has-real-cost-78billion.html (accessed 5 July 2020).

Tabachnick, B.G., Fidell, L.S. and Ullman, J.B. (2007), Using Multivariate Statistics, Pearson, Boston, Massachusetts, MA, Vol. 5.

Talwar, S., Dhir, A., Kaur, P., Zafar, N. and Alrasheedy, M. (2019), "Why do people share fake news? Associations between the dark side of social media use and fake news sharing behaviour", Journal of Retailing and Consumer Services, Vol. 51, pp. 72-82, doi: 10.1016/j.jretconser.2019.05.026.

Talwar, S., Dhir, A., Singh, D., Virk, G.S. and Salo, J. (2020), "Sharing of fake news on social media: application of the honeycomb framework and the third-person effect hypothesis", Journal of Retailing and Consumer Services, Vol. 57, 102197, doi: 10.1016/j.jretconser.2020.102197.

Talwar, S., Jabeen, F., Tandon, A., Sakashita, M. and Dhir, A. (2021), "What drives willingness to purchase and stated buying behavior towards organic food? A stimulus-organism-behaviorconsequence (SOBC) perspective", Journal of Cleaner Production, Vol. 293, 125882.

Tandon, A., Jabeen, F., Talwar, S., Sakashita, M. and Dhir, A. (2021), "Facilitators and inhibitors of organic food buying behavior", Food Quality and Preference, Vol. 88, 104077, doi: 10.1016/j.foodqual.2020.104077.

Thøgersen, J. (2007), “Consumer decision-making with regard to organic food products”, in Vaz, M.T.D.N., Vaz, P., Nijkamp, P. and Rastoin, J.L. (Eds), Traditional Food Production Facing Sustainability: A European Challenge, Ashgate, Farnham.

Thøgersen, J. and Zhou, Y. (2012), “Chinese consumers' adoption of a 'green' innovation-The case of organic food”, Journal of Marketing Management, Vol. 28 Nos 3-4, pp. 313-333, doi: 10.1080/0267257X.2012.658834.

Thøgersen, J., de Barcellos, M.D., Perin, M.G. and Zhou, Y. (2015), “Consumer buying motives and attitudes towards organic food in two emerging markets: China and Brazil”, International Marketing Review, Vol. 32 Nos 3/4, pp. 389-413, doi: 10.1108/IMR-06-2013-0123.

Thøgersen, J., Pedersen, S., Paternoga, M., Schwendel, E. and Aschemann-Witzel, J. (2017), "How important is country-of-origin for organic food consumers? A review of the literature and suggestions for future research", British Food Journal, Vol. 119 No. 3, pp. 542-557, doi: 10.1108/BFJ-09-2016-0406.

Tiainen, A.M.K., Mannisto, S., Lahti, M., Blomstedt, P.A., Lahti, J., Per€al€a, M.M. and Eriksson, J.G. (2013), "Personality and dietary intake-findings in the Helsinki birth cohort study", PloS One, Vol. 8 No. 7, e68284.

Van Huy, L., Chi, M.T.T., Lobo, A., Nguyen, N. and Long, P.H. (2019), "Effective segmentation of organic food consumers in Vietnam using food-related lifestyles”, Sustainability, Vol. 11 No. 5, p. 1237, doi: 10.3390/su11051237.

Verneau, F., Griffith, C.J., Porral, C.C. and Levy-Mangin, J.-P. (2016), "Food private label brands: the role of consumer trust on loyalty and purchase intention", British Food Journal, Vol. 118 No. 3, pp. 679-696, doi: 10.1108/BFJ-08-2015-0299.

Visentin, M., Pizzi, G. and Pichierri, M. (2019), "Fake news, real problems for brands: the impact of content truthfulness and source credibility on consumers' behavioral intentions towards the advertised brands", Journal of Interactive Marketing, Vol. 45, pp. 99-112, doi: 10.1016/j.intmar.2018.09.001.

Vosoughi, S., Roy, D. and Aral, S. (2018), “The spread of true and false news online”, Science, Vol. 359 No. 6380, pp. 1146-1151, doi: 10.1126/science.aap9559.

Wang, G., Dou, W. and Zhou, N. (2008), "Consumption attitudes and adoption of new consumer products: a contingency approach”, European Journal of Marketing, Vol. 42, pp. 238-254. 
Yee, W.M., Yeung, R.M. and Morris, J. (2005), "Food safety: building consumer trust in livestock farmers for potential purchase behaviour", British Food Journal.

Zheng, Y. and Liu, C. (2019), "The predictors of consumer behavior in relation to organic food in the context of food safety incidents: advancing hyper attention theory within an stimulusorganismresponse model", Frontiers in Psychology, Vol. 10, p. 2512, doi: 10.3389/fpsyg.2019.02512. 